\title{
Effect of flapless ridge preservation with two different alloplastic materials in sockets with buccal dehiscence defects-volumetric and linear changes
}

\author{
Naenni, Nadja ; Sapata, Vitor ; Bienz, Stefan P ; Leventis, Minas ; Jung, Ronald E ; Hämmerle, Christoph H F ;
} Thoma, Daniel S

\begin{abstract}
OBJECTIVE:To test whether or not one out of two alloplastic materials used for ridge preservation $(\mathrm{RP})$ is superior to the other in terms of volumetric and linear ridge changes over time. MATERIALS AND METHODS:In 16 adult beagle dogs, the distal roots of P3 and P4 were extracted and $50 \%$ of the buccal bone plate removed. Ridge preservation was performed randomly using two different alloplastic bone grafting substitutes (poly lactic-co-glycolic acid (PLGA) coated biphasic calcium phosphate particles consisting of $60 \%$ hydroxyapatite (HA) and $40 \%$ beta-tricalcium phosphate ( $\beta-\mathrm{TCP}=$ test 1 ), (a biphasic calcium phosphate consisting $60 \% \mathrm{HA}$ and $40 \%$ B-TCP=test 2 ) and a resorbable collagen membrane or a control group (sham). Sacrifice was performed at three time-points $(4,8,16$ weeks later). Impressions were taken before extraction, after RP, and at sacrifice, allowing for assessment of volumetric changes. A multi-way ANOVA was computed, and partial Type-II F tests were performed. RESULTS:Both ridge preservation procedures minimized the volume loss compared to spontaneous healing. The median buccal volume changes between pre-extraction and sacrifice were $-1.76 \mathrm{~mm}(\mathrm{Q} 1=$ - 2.56; $\mathrm{Q} 3=-1.42)$ for test $1,-1.62 \mathrm{~mm}(\mathrm{Q} 1=-2.06$; $\mathrm{Q} 3=-1.38)$ for test 2 , and $-2.42 \mathrm{~mm}(\mathrm{Q} 1=-2.63$; Q3 = 2.03) for control. The mean ridge width measurements did not show statistically significant differences between test $1(-2.51 \mathrm{~mm} ; \mathrm{Q} 1=-3.25 ; \mathrm{Q} 3=-1.70)$ and test $2(-2.04 \mathrm{~mm}$; $\mathrm{Q} 1=-3.82 ; \mathrm{Q} 3=-1.81)(\mathrm{p}=0.813)$, but between test and control $(-3.85 \mathrm{~mm}$; $\mathrm{Q} 1=-5.02$; $\mathrm{Q} 3=-3.27)(\mathrm{p}=0.003)$. CONCLUSIONS:Both RP techniques were successful in maintaining the buccal contour from pre-extraction to sacrifice to a similar extent and more favorable compared to spontaneous healing. CLINICAL RELEVANCE:Alloplastic materials can successfully be used for RP procedures.
\end{abstract}

DOI: https://doi.org/10.1007/s00784-017-2309-6

Posted at the Zurich Open Repository and Archive, University of Zurich ZORA URL: https://doi.org/10.5167/uzh-150978

Journal Article

Accepted Version

Originally published at:

Naenni, Nadja; Sapata, Vitor; Bienz, Stefan P; Leventis, Minas; Jung, Ronald E; Hämmerle, Christoph H F; Thoma, Daniel S (2018). Effect of flapless ridge preservation with two different alloplastic materials in sockets with buccal dehiscence defects-volumetric and linear changes. Clinical Oral Investigations, 22(6):2187-2197.

DOI: https://doi.org/10.1007/s00784-017-2309-6 


\section{Effect of flapless ridge preservation with two different alloplastic materials in sockets with buccal dehiscence defects- volumetric and linear changes}

Nadja Naenni ${ }^{1}$, Vitor Sapata ${ }^{1}$, Stefan P. Bienz ${ }^{1}$, Minas Leventis ${ }^{2}$, Ronald E. Jung ${ }^{1}$, Christoph H.F. Hämmerle ${ }^{1}$, Daniel S. Thoma ${ }^{1}$

${ }^{1}$ Clinic of Fixed and Removable Prosthodontics and Dental Material Science, Center of Dental Medicine, University of Zurich, Zurich, Switzerland

2 Laboratory of Experimental Surgery and Surgical Research N. S. Christeas, Medical School, University of Athens, Athens, Greece

Key words: ridge preservation, volume stability, alveolar ridge augmentation (MeSH)

Running title: ridge preservation alloplastic materials

Address for correspondence: $\quad$ PD Dr. Daniel S. Thoma

Clinic of Fixed and Removable Prosthodontics and Dental Material Science

Center of Dental Medicine, University of Zurich

Plattenstrasse 11

$\mathrm{CH}-8032$ Zurich, Switzerland

Phone: +41446343260

Fax: +41446344305

e-mail: daniel.thoma@zzm.uzh.ch

\section{Acknowledgements and conflict of interest}

The authors would like to acknowledge Dr. M. Mayer, for his support in the statistical analysis of the data and the animal care team at NAMSA, Lyon, France for assistance during surgery. The support and expertise of Dr. Lorenz Uebersax, Sunstar Suisse SA, Etoy, Switzerland, is highly appreciated. This study was funded by Sunstar Suisse SA, Etoy, Switzerland and the Clinic of Fixed and Removable Prosthodontics and Dental Material Science, Center of Dental Medicine, University of Zurich, Zurich, Switzerland. 


\begin{abstract}
Objective: To test whether or not one out of two alloplastic materials used for ridge preservation (RP) is superior to the other in terms of volumetric and linear ridge changes over time.
\end{abstract}

Materials and methods: In sixteen adult beagle dogs, the distal roots of P3 and P4 were extracted and $50 \%$ of the buccal bone plate removed. Ridge preservation was performed randomly using two different alloplastic bone grafting substitute (poly lacticco-glycolic acid (PLGA) coated biphasic calcium phosphate particles consisting of $60 \%$ hydroxyapatite (HA) and $40 \%$ beta-tricalcium phosphate ( $B$-TCP=test 1 ), (a biphasic calcium phosphate consisting $60 \% \mathrm{HA}$ and $40 \% \mathrm{~B}-\mathrm{TCP}=$ test 2 ) and a resorbable collagen membrane or a control group (sham). Sacrifice was performed at three time-points (4, 8, 16 weeks later). Impressions were taken before extraction, after RP and at sacrifice, allowing for assessment of volumetric changes. A multi-way ANOVA was computed and partial Type-II $\mathrm{F}$ tests were performed.

Results: Both ridge preservation procedures minimized the volume loss compared to spontaneous healing. The median buccal volume changes between pre-extraction and sacrifice were $-1.76 \mathrm{~mm}(\mathrm{Q} 1=-2.56 ; \mathrm{Q} 3=-1.42)$ for test $1,-1.62 \mathrm{~mm}(\mathrm{Q} 1=-2.06 ; \mathrm{Q} 3=$ $-1.38)$ for test 2 and $-2.42 \mathrm{~mm}(\mathrm{Q} 1=-2.63 ; \mathrm{Q} 3=-2.03)$ for control. The mean ridge width measurements did not show statistically significant differences between test 1 ($2.51 \mathrm{~mm} ; \mathrm{Q} 1=-3.25 ; \mathrm{Q} 3=-1.70)$ and test $2(-2.04 \mathrm{~mm} ; \mathrm{Q} 1=-3.82 ; \mathrm{Q} 3=-$ $1.81)(p=0.813)$, but between test and control $(-3.85 \mathrm{~mm} ; \mathrm{Q} 1=-5.02 ; \mathrm{Q} 3=-$ $3.27)(p=0.003)$.

Conclusions: Both RP techniques were successful in maintaining the buccal contour from pre-extraction to sacrifice to a similar extent and more favorable compared to spontaneous healing.

Clinical Relevance: Alloplastic materials can successfully be used for RP procedures. 


\section{Introduction}

The remodeling and resorption processes following tooth extraction have been investigated in detail in a variety of preclinical and clinical studies. Based on these data, resorption of the buccal bone contour extends up to 12 months after extraction. A mean resorption of approximately $50 \%$ is taking place predominantly during the first three months. (Schropp et al., 2003, Tan et al., 2012, Jung et al., 2013, Atwood, 2001, Tallgren, 1972). The loss of volume on both, the hard and the soft tissue level, influences the placement of dental implants and the subsequent aesthetic outcome. Therefore, additional bone augmentation procedures at the day of implant placement are often required. In order to limit the contour changes, ridge preservation procedures were proposed, demonstrating that resorption and remodeling processes can be limited to a loss of 7.7\%-20\% (Jung et al., 2013, Araujo and Lindhe, 2009, Lindhe et al., 2014, Cardaropoli et al., 2012). Although the use of grafting materials for the purpose of ridge preservation can be an effective therapy to limit phyisological changes of the vertical and horizontal dimension (Avila-Ortiz et al., 2014), it remains unclear which material and technique works best in preserving the ridge contour. In addition, the impact of ridge preservation techniques on subsequent augmentation surgeries and long-term results of dental implants remains unclear in the literature (Mardas et al., 2015, Vignoletti et al., 2012). The obtained data are to some extent limited by: i) strict inclusion criteria, ii) the use of predominantly xenogeneic bone substitute materials (Artzi et al., 2000, Barone et al., 2008), iii) volume measurements are restricted to post-extraction/after ridge preservation and the follow-up measurements, with few exceptions (Barone et al., $\underline{2015})$.

Clinicians often encounter situations where the strict inclusion criteria applied in most of the studies are not met and extraction sites might exhibit a loss of $50 \%$ of the buccal bone. Indications for ridge preservation procedures should therefore be expanded to sites with an enhanced loss of the buccal bone plate (Sisti et al., 2012, Spinato et al., 2014). Moreover, from a patient's perspective, there is an increasing demand for 
synthetic materials. Available synthetic materials often consist of varying combinations of HA/TCP and are indicated for different clinical scenarios including ridge preservation, sinus grafting and guided bone regeneration (Araujo et al., 2010, Froum and Orlowski, 2000, Horowitz et al., 2009). Outcomes based on preclinical and clinical data are controversial when compared to the use of xenogeneic materials (Lee et al., 2009, Shi et al., 2007). Still, the scientific data for the use of alloplastic materials for ridge preservation procedures is limited.

In addition, one of the major limitations of current preclinical and clinical studies is the timing of the evaluated contour changes following ridge preservation procedures (Mardas et al., 2015). Even though data demonstrate a relatively low loss of volume between post ridge preservation and the investigated follow-up time-points, the changes between the preoperative situation (prior to extraction) and postoperative situation (immediately after ridge preservation) have not been assessed so far. Thus, it is speculated that ridge preservation procedures might be overestimated, since they do not take into account a potential loss of volume due to the surgical procedure itself (i.e. tooth extraction). Moreover, depending on the anatomical situation and the present hard and soft tissue deficits, ridge preservation procedures are performed using a flapless approach ( $\underline{\mathrm{Jung}}$, 2017). Hence, within this study flapless tooth extraction and ridge preservation was performed.

The aims of the present study were, therefore, to test whether or not one out of two alloplastic materials for ridge preservation applied in extraction sockets with dehiscence defects is superior to the other and compared to sham-operated control sites as measured by linear and volumetric changes between pre-extraction, after ridge preservation and at 4, 8 and 16 weeks of healing. 


\section{Materials and Methods:}

\section{Study design}

The present study was performed as a randomized controlled experimental study. Sixteen adult male beagle dogs (more than 1-year-old, weighing between 10 to $20 \mathrm{~kg}$ ) were used. During the study, the animals were kept in a purpose-designed room and fed a soft diet. The protocol was approved by the local ethical committee of NAMSA (Lyon, France) and conducted in accordance with the OECD Good Laboratory Practice regulations, ENV/MC/CHEM (98) 17, with the European Good Laboratory Practice regulations, 2004/10/EC Directive and with the United States Food and Drug Administration Good Laboratory Practice regulations, 21 CFR 58. The manuscript has been written according to the ARRIVE guidelines (Kilkenny et al., 2011).

\section{Preparation and medication}

Spiramycin and metronidazole (Buccoval ${ }^{\circledR}$, Sogeval) were administered per os (oral administration) and penicillin procaine and benzathine (Duplocilline ${ }^{\circledR}$, Intervet S.A) were injected subcutaneously for antimicrobial prophylaxis the day before surgery. At the day of the surgery, the dogs were weighed and anesthetized. After an intramuscular injection of medetomidine (Dorbene Vet $^{\circledR}$, Pfizer), anesthesia was induced by intravenous administration of ketamine (Ketamine $1000^{\circledR}$, Virbac) followed by inhalation of an $\mathrm{O}_{2}-$ isoflurane mixture (Isoflo ${ }^{\circledR}$, Axience). A pre-operative subcutaneous injection of carprofene (Rimadyl ${ }^{\circledR}$, Pfizer) and buprenorphine (Buprecare ${ }^{\circledR}$, Axience) was administered. The mandibles were disinfected with application of $0.2 \%$ chlorhexidine (Cooper) and the surgical region was locally anesthetized. Postoperatively, Spiramycin and metronidazole (per os, $75000 \mathrm{IU} / \mathrm{kg}$ of spiramycine and $12,5 \mathrm{mg} / \mathrm{kg}$ of metronidazole, Buccoval ${ }^{\circledR}$, Sogeval) were administered daily, for at least 14 days for antimicrobial prophylaxis. Carprofene (per os, $4 \mathrm{mg} / \mathrm{kg}$ Carprodyl ${ }^{\circledR}$, CEVA) was administered daily for at least 5 days as anti-inflammatory drug. Postoperative pain was controlled with Buprenorphine (SC, $0.01 \mathrm{mg} / \mathrm{kg}$, Buprecare ${ }^{\circledR}$, Axience), it was injected 
when needed. For local disinfection, Chlorhexidine $(0.2 \%$, Cooper $)$ was applied on the sites once a day until wound healing was complete.

\section{Extractions and ridge preservation}

Three calibrated surgeons performed all the treatments. On both sides of the mandible in all dogs, the distal roots of P3 and P4 were extracted without raising a flap (Fig. 1a, 1b). Root canal treatment was performed for the mesial root of P3 and P4 (Thoma et al., 2010). Subsequently, a split-thickness flap was prepared on the lingual and buccal side extending up to the apical extension of the extraction socket (vertically) and $2 \mathrm{~mm}$ mesial and distal of the extraction socket (horizontally). Then, $50 \%$ of the buccal bone was carefully removed using a bur. A total number of 62 extraction sites was prepared, four extraction sites in each of the 15 dogs and only two extraction sites in one dog (the two P4 were missing). Extraction sites (the distal roots of P3 and P4) were randomly assigned to one of the following treatments (Table 1). Based on a sample size calculation, the randomization of groups and sites was performed by the GLP approved lab (NAMSA, Lyon, France) prior to the start of the investigation:

- Test group 1 (test 1): in situ hardening alloplastic bone substitute material (poly lactic-co-glycolic acid (PLGA) coated biphasic calcium phosphate particles consisting of $60 \%$ hydroxyapatite $(\mathrm{HA})$ and $40 \%$ beta-tricalcium phosphate (BTCP), GUIDOR easy-graft CRYSTAL, Sunstar Suisse SA, Switzerland) + collagen membrane (Jason Membrane, Botiss Biomaterials GmbH, Zossen, Germany).

- Test group 2 (test 2): alloplastic bone substitute material (biphasic calcium phosphate consisting: $60 \% \mathrm{HA}$ and $40 \%$ B-TCP; Straumann ${ }^{\circledR}$ BoneCeramic, Institut Straumann AG, Basel, Switzerland) + collagen membrane (Jason Membrane, Botiss Biomaterials $\mathrm{GmbH}$ ).

- Control group (sham): negative control, blood clot.

In the test groups the extraction sites were filled with the respective alloplastic bone graft up to the level of the bone crest (prior to extraction at the buccal aspect) without overfilling the buccal contour, following the manufacturer's instruction for use (Fig. 1c). 
A collagen membrane was placed underneath the buccal and lingual soft tissue, thereby covering the bone graft material (Fig. 1d). In the sham-operated sites (control), a coagulum was allowed to form (Fig. 1f) and no biomaterials were used. Partial wound closure was obtained in all groups applying a horizontal mattress suture (Fig. 1e, 1f). Sutures were removed 13 to 14 days after ridge preservation. Healing was assessed on inspection at the time of suture removal and again at the day of sacrifice.

\section{Sacrifice}

Four, 8 and 16 weeks after ridge preservation, all dogs were painlessly sacrificed using an overdose of pentobarbital (60 mg/kg/i.v., Dolethal; Vetoquinol, France) after sedation with tiletamine-zolazepam (25 mg/kg, IM, Zoletil ${ }^{\circledR} 100$, Virbac). The present manuscript reports on volumetric and linear changes of the sites. Histologic data will be published in a subsequent manuscript.

\section{Dental impressions}

Individualized trays made of light-curing tray material (Megatray ${ }^{\circledR}$, Select Dental Manufacturing Company, Farmingdale, NY, USA) were used for impressions. Impressions of the mandibles were taken using a polyether material (Permadyne, 3M ESPE, Rüschlikon, Switzerland) at baseline (pre-extraction, T1), after ridge preservation (postoperative, T2) and at sacrifice (T3). At T3, three healing periods were obtained (4, 8, and 16 weeks after ridge preservation). Dental stone (GC Fujirock ${ }^{\circledR}$ type 4, GC Corporation, Tokyo, Japan) was poured to fabricate the master casts. On the casts obtained at T1 (prior to tooth extraction), the mesial parts of the crowns were removed using a drill up to the level of the gingiva in order to simulate an ideal ridge profile serving as baseline. Subsequently, all casts were scanned using a dental 3D scanner (Imetric 3D SA, Courgenay, Switzerland) to obtain stereolithographic (STL) files. 


\section{Linear and volumetric analyses}

A specifically designed software (SMOP, Swissmeda, Zurich, Switzerland) was used to superimpose the acquired STL files. The superimposition allowed the calculation of linear and volumetric changes of the sites over time. An experienced examiner unaware of the treatment groups performed all the measurements at the University of Zurich (GLP like conditions).

\section{Volumetric measurements}

At the buccal aspect of the sites, the measured area was manually selected on the baseline (T1) STL file. The selected region of interest (ROI) corresponded to a polygon $0.5 \mathrm{~mm}$ apically from the transition between the buccal and occlusal plane and extended $2 \mathrm{~mm}$ in an apical direction, with a mesio-distal width of $2 \mathrm{~mm}$ (Fig. 2a,c). For the occlusal measurement, a polygon with a similar dimension was used in the center of the (former) extraction site (Fig. $2 b, c)$. The volumes as well as the mean distance (MD, mm) between the surfaces within the ROI were measured by the software. The size of the ROI varied among the sites (P3, P4) as well as between individuals. Therefore, the data are presented as a mean distance between two surfaces, due to the fact that this value is highly independent of the size of the selected area compared to a volumetric value.

\section{Linear measurements}

The total bucco-lingual ridge width $(\mathrm{RW}, \mathrm{mm})$ was measured at three levels (RW-1 at 1 $\mathrm{mm}, \mathrm{RW}-2$ at $2 \mathrm{~mm}$ and $\mathrm{RW}-3$ at $3 \mathrm{~mm}$ ) below the zenith of the ridge. The RW changes were calculated (in percentages; \%) between T1-T2, T2-T3 and T1-T3. A cross-section was chosen, dividing the region of interest (ROI) of the volumetric measurements into two equal parts. The adjacent teeth were used to determine the longitudinal axis of the ridge. Subsequently, a reference line was drawn tangent to the zenith of the ridge on the baseline (T1) STL surface. The measurements at the three levels were performed and calculated orthogonally to the longitudinal axis of the ridge (Fig. 3). 
Statistical analysis

Data were computed in Excel (Microsoft Corporation, Redmond, USA) and statistical analysis was performed with R (R Core Team (2016). R: A language and environment for statistical computing. R Foundation for Statistical Computing, Vienna, Austria.

https://www.R-project.org/). The distributions of all endpoints (differences over time in volumetric and linear measurements) are described by counts, means, standard deviations and quartiles stratified by treatment or by treatment and healing periods. To compare mean measurement differences over time in an exploratory way, as a simple approach, a multi-way ANOVA was computed not accounting for potential intra-dog correlations, i.e. by assuming measurements from the same dog to be statistically independent. The factors considered are treatment, healing duration (where T3 is involved) and site (all without interactions). Partial Type-II F tests were performed for overall treatment effects and then, if significant at the level of 5\%, also the two pairwise t-tests of specific interest, i.e. test versus each control group (done at the $2.5 \%$ level to not inflate the family wise error rate). As a sensitivity analysis to this simple approach, we adjusted these ANOVAs for intra-dog correlations by using random dog and side within dog random intercepts in a mixed effects model framework. 


\section{Results:}

Healing

General healing in all dogs was uneventful and neither wound healing complications nor local infections were observed at the follow-up time-points. At suture removal, in 13 out 62 sites, the wound was not completely closed ( 8 test 1, 4 test 2 and 1 sham site). Thereafter, at all further healing time-points, complete wound closure was observed (Fig. 1g,h).

The descriptive results are presented with pooled healing periods for all time periods in figure 4. Throughout the following section, the time-points from pre-extraction to postoperative (T1-T2) and pre-extraction to sacrifice (T1-T3) are as well presented with pooled healing periods, while the period from post-operative to sacrifice (T2-T3) is presented with separated healing periods for all parameters. $\mathrm{P}$ values are adjusted for healing period effects as long as the sacrifice time-points were involved in the differences.

\section{Volumetric measurements, buccal}

In general, the buccal volume decreased over time for all treatments. The buccal volume changes between pre-extraction and sacrifice (T1-T3) revealed median values of -1.76 $\mathrm{mm}(\mathrm{Q} 1=-2.56 ; \mathrm{Q} 3=-1.42)$ for test 1 , of $-1.62 \mathrm{~mm}(\mathrm{Q} 1=-2.06 ; \mathrm{Q} 3=-1.38)$ for test 2 and of $-2.42 \mathrm{~mm}(\mathrm{Q} 1=-2.63 ; \mathrm{Q} 3=-2.03)$ for control (sham). No statistically significant differences were found between test 1 and test $2(p=0.396)$ and between test 1 and control $(p=0.028)$ at the $2.5 \%$ level. The model approach accounting for within dog dependencies revealed statistical significance between test 1 and control $(p=0.012)$.

Due to the extraction and the subsequent surgical procedure (T1-T2), a median loss of $0.27 \mathrm{~mm}(\mathrm{Q} 1=-0.54 ; \mathrm{Q} 3=-0.13)$ (test 1$),-0.70 \mathrm{~mm}(\mathrm{Q} 1=-0.89 ; \mathrm{Q} 3=-0.53)$ (test 2) and $-1.43 \mathrm{~mm}(\mathrm{Q} 1=-1.99 ; \mathrm{Q} 3=-0.83)$ (control) was calculated. Again, no 
statistically significant difference was found between test 1 and test $2(p=0.124)$, but between test 1 and control $(p<0.0001)$.

Comparing the healing periods (post-operative to sacrifice; T2-T3), the test 1 group presented a median decrease of $-1.08 \mathrm{~mm}(\mathrm{Q} 1=-1.27 ; \mathrm{Q} 3=-0.93)$ after a healing period of 4 weeks, $-1.84 \mathrm{~mm}(\mathrm{Q} 1=-2.24 ; \mathrm{Q} 3=-1.28)$ at 8 weeks and $-1.44 \mathrm{~mm}(\mathrm{Q} 1=$ $-1.92 ; \mathrm{Q} 3=-0.93)$ at 16 weeks. The test 2 group showed a median loss of $-0.88 \mathrm{~mm}$ $(\mathrm{Q} 1=-1.20 ; \mathrm{Q} 3=-0.65)$ at 4 weeks, $-0.93 \mathrm{~mm}(\mathrm{Q} 1=-1.96 ; \mathrm{Q} 3=-0.69)$ at 8 weeks and $-0.83 \mathrm{~mm}(\mathrm{Q} 1=-0.99 ; \mathrm{Q} 3=-0.49)$ at 16 weeks, and the control group demonstrated a median loss of $-0.71 \mathrm{~mm}(\mathrm{Q} 1=-1.40 ; \mathrm{Q} 3=0.10)$ at 4 weeks, -1.09 $\mathrm{mm}(\mathrm{Q} 1=-1.51 ; \mathrm{Q} 3=-0.80)$ at 8 weeks and $-1.01 \mathrm{~mm}(\mathrm{Q} 1=-1.22 ; \mathrm{Q} 3=-0.04)$ at 16 weeks. All buccal measurements are presented in table $2 \mathrm{a} / \mathrm{b}$.

Volumetric measurements, occlusal

The pooled data for occlusal volume changes between pre-extraction and sacrifice (T1T3) revealed median values of $-0.79 \mathrm{~mm}(\mathrm{Q} 1=-1.47 ; \mathrm{Q} 3=-0.42)$ for test 1 , of -0.55 $\mathrm{mm}(\mathrm{Q} 1=-1.37 ; \mathrm{Q} 3=-0.05)$ for test 2 and of $-1.19 \mathrm{~mm}(\mathrm{Q} 1=-1.80 ; \mathrm{Q} 3=-0.93)$ for control. No statistically significant difference was found between test 1 and test 2 $(p=0.514)$ and, but between test 1 and control $(p=0.033)$.

The changes due to the surgical procedure (T1-T2) revealed a median volume loss ranging between $-0.39 \mathrm{~mm}(\mathrm{Q} 1=-0.79 ; \mathrm{Q} 3=-0.19)$ for test $1,-0.82 \mathrm{~mm}(\mathrm{Q} 1=-1.02$; $\mathrm{Q} 3=-0.57)$ for test 2 and $-1.74 \mathrm{~mm}(\mathrm{Q} 1=-2.34 ; \mathrm{Q} 3=-1.57)$ for group control. There was no statistically significant difference between test 1 and test $2(p=0.058)$, but between test 1 and control $(p<0.0001)$. All occlusal measurements are presented in table $2 \mathrm{a} / \mathrm{b}$. 
Linear measurements, ridge width changes (RW)

The pooled data for ridge width changes at $3 \mathrm{~mm}$ below the crest (RW-3) between preextraction and all three sacrifice time-points (T1-T3) did not differ statistically significantly between test $1(-1.22 \mathrm{~mm} ; \mathrm{Q} 1=-2.33 ; \mathrm{Q} 3=-0.23)$ and test $2(-1.16 \mathrm{~mm}$; $\mathrm{Q} 1=-2.15 ; \mathrm{Q} 3=-0.75)(\mathrm{p}=0.949)$, but for control $(-2.5 \mathrm{~mm} ; \mathrm{Q} 1=-3.34 ; \mathrm{Q} 3=-2.07)$ compared to test $1(p=0.0003)$.

The surgical intervention (T1-T2) increased the total ridge width at $3 \mathrm{~mm}$ below the crest (RW-3) in the test 1 group $(1.64 \mathrm{~mm} ; \mathrm{Q} 1=1.17 ; \mathrm{Q} 3=2.11)$ and in the test 2 group $(0.85 \mathrm{~mm} ; \mathrm{Q} 1=0.59 ; \mathrm{Q} 3=1.70)(\mathrm{p}=0.131)$. The model approach accounting for within dog dependencies revealed statistical significance between test 1 and test 2 $(p=0.0041)$. Control sites lost $-0.35 \mathrm{~mm}(\mathrm{Q} 1=-0.87 ; \mathrm{Q} 3=0.32)$, being statistically significantly different compared to test $1(p<0.0001)$.

During the further healing period (T2-T3), the ridge width lost between $-1.88 \mathrm{~mm}(\mathrm{Q} 1=$ -2.46; $\mathrm{Q} 3=-1.25)($ minimal: sham at the 8-week sacrifice) and $-3.68 \mathrm{~mm}(\mathrm{Q} 1=-4.66$; $\mathrm{Q} 3=-2.89$ ) (maximal: test at the 8-week sacrifice). The measurements of the total ridge width changes $(\mathrm{mm})$ at $1 \mathrm{~mm}, 2 \mathrm{~mm}$ and $3 \mathrm{~mm}$ below the zenith of the ridge are presented in table $2 \mathrm{c} / \mathrm{d}$.

Linear measurements, Ridge width changes averaged for all three levels ( $R W-1, R W-2$, $R W-3)$

When healing periods ( $\mathrm{T} 1$ to $\mathrm{T} 3$ for all sacrifice time-points) were pooled and ridge width changes on the different levels averaged, no statistically significant differences were found between test $1(-2.51 \mathrm{~mm} ; \mathrm{Q} 1=-3.25 ; \mathrm{Q} 3=-1.70)$ and test $2(-2.04 \mathrm{~mm}$; $\mathrm{Q} 1=$ $-3.82 ; \mathrm{Q} 3=-1.81)(\mathrm{p}=0.813)$, but between test 1 and control $(-3.85 \mathrm{~mm} ; \mathrm{Q} 1=-5.02$; $\mathrm{Q} 3=-3.27)(\mathrm{p}=0.003)$. For $\mathrm{T} 1-\mathrm{T} 2$, the higher gain found for test $1(0.59 \mathrm{~mm}$; $\mathrm{Q} 1=$ $0.14 ; \mathrm{Q} 3=0.79)$ was not statistically significant compared to test $2(-0.13 \mathrm{~mm} ; \mathrm{Q} 1=-$ 
$0.39 ; \mathrm{Q} 3=0.30)(\mathrm{p}=0.039)$, but compared to control $(-2.09 \mathrm{~mm} ; \mathrm{Q} 1=-2.80 ; \mathrm{Q} 3=-$ $0.89)(p<0.0001)$. A representative cross-section of each group is shown in figure 5. 


\section{Discussion:}

The present experimental study revealed that i) ridge preservation procedures minimized the volume loss due to the surgical intervention compared to spontaneous healing; ii) the majority of volume loss occurs within the first weeks post extraction; iii) in sites with a partial loss of the buccal bone plate, ridge preservation procedures are beneficial demonstrating a more stable ridge profile over time compared to sites healing spontaneously; iv) both ridge preservation treatments resulted in similar volumetric and linear changes of the ridge profile over time.

There is plenty of scientific evidence reporting changes of the alveolar ridge profile following tooth extraction. For sites healing spontaneously, the loss is reported to be $50 \%$, whereas ridge preservation procedures may limit these changes to $7 \%-20 \%$ (Araujo and Lindhe, 2009, Jung et al., 2013, Lindhe et al., 2014, Cardaropoli et al., 2012). As the present study clearly points out, volume loss can already be observed due to the surgical intervention (i.e. tooth extraction), a fact that was documented in a previous study (Barone et al., 2015). However, when critically analyzing the data from the literature, it becomes obvious that in the majority of the studies, the changes following tooth extraction were calculated between two time-points only. This predominantly included pre-extraction to follow-up or post-extraction to a specific followup time-point. For sites subjected to spontaneous healing this amounted to a loss of buccal $(-1.4 \mathrm{~mm})$ and occlusal $(-1.7 \mathrm{~mm})$ volume, as well as of ridge width $(-0.4 \mathrm{~mm})$ in the presented study. Ridge preservation procedures limited the loss of buccal and occlusal volume (range between $-0.3 \mathrm{~mm}$ to $-0.8 \mathrm{~mm}$ ). The ridge width, however, increased compared to the time-point prior to tooth extraction $(+1.6 \mathrm{~mm}$ for test 1 and $+0.6 \mathrm{~mm}$ for test 2 ). These data underline that for spontaneous healing, the obtained loss at the follow-up might be underestimated when considering the situation post- extraction immediately after extraction. For ridge preservation procedures, the effect of the various techniques might be overestimated based on buccal and occlusal volume analyses, but not for the ridge width. This is due to the fact that from a clinical point of view, the goal 
should be to obtain a contour and ridge width similar to what existed prior to tooth extraction and not a contour after tooth extraction (as usually accepted when using a post-extraction time-point as baseline time-point).

Observational studies on ridge alterations following tooth extraction reported that volume loss predominantly occur within the first weeks, whereas thereafter, changes are limited (Rothamel et al., 2008, Araujo and Lindhe, 2005). In the present study, the majority of volume loss was observed at 1 month following extraction and ridge preservation/spontaneous healing. The changes observed at the later follow-up timepoints 8 and 16 weeks were minimal and even indicated stability of the ridge sites. Ridge alterations are based on an increase in soft tissue thickness, an increase in bone formation and ongoing remodeling processes. At early time-points, remodeling process mainly include partial or complete resorption of the buccal bone plate and wound closure due to soft tissue regeneration. At later time-points, remodeling processes predominantly encompass new bone formation within the former extraction socket and maturation processes. These processes were studied in a variety of preclinical studies in detail (Cardaropoli et al., 2003, Araujo and Lindhe, 2005). The observed volume changes in the present study corroborate with previous experiments. Soft tissue wound closure was obtained in all sites at 4 weeks, irrespective of the applied treatment modality and without complete wound closure at the day of tooth extraction. Further on, only minimal ridge alterations were detected.

Ridge preservation procedures are reported to be beneficial for a number of reasons. This includes: an enhanced stability of the ridge profile following tooth extraction, less necessity for bone regenerative procedures at the day of implant placement and an improved soft tissue quality and quantity (Barone et al., 2013, Barone et al., 2012, Lindhe et al., 2014). The present study clearly demonstrated that both test groups (ridge preservation with alloplastic bone substitute material) limited alveolar ridge volume and width changes compared to sites healing spontaneously. Even though no implants were 
placed and the quality of hard and soft tissues not assessed, benefits from a clinical point of view and in terms of maintenance of the ridge profile and volume are obvious. Whether or not the soft and hard tissue quality supports clinical outcomes has to be investigated using histologic and histomorphometric analyses.

Both treatment modalities used for ridge preservation resulted in similar changes of the ridge profile as assessed by volumetric and linear outcome measures. The only difference between the two treatments was the applied bone substitute material, whereas the membrane used to cover the augmented extraction socket was similar. From a clinical point of view, the handling in the test 1 group allowed a simpler approach with the bone substitute material being provided in a syringe. Once applied, the material hardened in situ and stayed in place. In the test 2 group, the alloplastic material was provided as granules, thereby increasing the difficulty to apply the material into the extraction socket. These differences in the clinical handling, with the easier approach in the test 1 group, resulted in a slightly increased ridge volume following ridge preservation. Over the course of the next months, this initially slightly higher volume was lost, resulting in a similar ridge dimension at the later sacrifice time-points. Synthetic bone substitute materials were used in the past for a variety of clinical indications (Araujo et al., 2010, Dahlin et al., 2015). Depending on the material composition, mainly influenced by the ratio of $\mathrm{HA}$ and $\mathrm{TCP}$, variable resorption rates and bone formation were observed in the different clinical scenarios (Horowitz et al., 2009). In a clinical study, an alloplastic material (similar to test group 2 in the present study) was investigated during an observation period of 6-8 months and compared to a xenogeneic bone substitute material. Both materials demonstrated to be osteoconductive and resulted in similar amounts of new bone formation. Histologic analyses showed the amount of residual graft particles to range between 26 and $28 \%$ in both, the alloplastic and the xenogeneic bone substitute material (Froum et al., 2008). In contrast, previous data on synthetic materials reported higher resorption rates than xenogeneic materials demonstrating a relatively long turn-over time (Jung et al., 2013, Jensen et al., 2009, Lee et al., 2009, 
Schneider et al., 2014). For test group 1, rather any scientific evidence is available. Only one clinical study reports on a case series in humans without providing any histologic outcome measures (Leventis 2014). Thus, this specific material still lacks scientific evidence and was therefore applied in the present study to obtain clinical as well as histologic data. In the present study, the use of a resorbable membrane is believed to have contributed to more favorable outcomes at least for two aspects: enhancing wound healing by protecting the underlying bone substitute materials and by providing a barrier function to increase bone formation (Kim et al., 2016). Even though it is known that resorbable membranes lack a space maintenance function, the defect morphology of an extraction socket certainly supported the ridge profile to be better maintained with a guided bone regeneration membrane. For extraction sites with a missing buccal bone plate, higher resorption rates are documented, however (Spinato et al., 2014, Scheyer et al., 2016). 


\section{Conclusions}

The two ridge preservation techniques applied in the present study were able to maintain the buccal contour at least in part without significant differences based on volumetric and linear outcome measures and were more favorable compared to sites left for spontaneous healing. 


\section{Figure legends}

Figure 1. Clinical situation showing the performed treatments. (a) before extraction; (b) after extraction without flap elevation, $50 \%$ of the buccal bone plate removed; (c) Inserted collagen membrane with respective bone regeneration material; (d) Adaptation of the membrane; (e), (f) Horizontal mattress suture. (g), (h) Clinical pictures after 16 weeks of healing at the time of sacrifice.

Figure 2. View of one jaw with the superimposed STL files. Yellow, green and grey models representing T1 (pre-extraction), T2 (post-operative) and T3 (sacrifice), respectively. (a) Occlusal view of the treated region. Blue areas representing the area of volumetric measurements. (b) Buccal view of superimposed STL files. (c) Cross-section with both measurements (orange).

Figure 3. Transversal slice of the ridge with the linear measurements. A reference line crossing the zenith of the ridge was drawn. Parallel lines at $1 \mathrm{~mm}(\mathrm{RW}-1), 2 \mathrm{~mm}(\mathrm{RW}-2)$ and $3 \mathrm{~mm}(\mathrm{RW}-3)$ were drawn, along them the ridge width was measured.

Figure 4. Buccal volume, occlusal volume and ridge width at $3 \mathrm{~mm}$ below the crest (RW3) with pooled healing periods, for pre-extraction to post-operative (T1-T2), postoperative to sacrifice (T2-T3) and pre-extraction to sacrifice (T1-T3).

Figure 5. Cross-sections with the buccal aspect on the left side of the picture for test 2 (a), test 1 (b) and control (c). Yellow, green and grey lines represent T1 (preextraction), T2 (post-operative) and T3 (sacrifice), respectively.

Table 1. Study schedule including number of dogs, treatments and sites per time-point. 
Table 2a. Volumetric measurements (mean distance, $\mathrm{mm}$ ) between pre-extraction (T1), post-operative (T2) and sacrifice (T3). BV: Buccal Volume; OV: Occlusal Volume; Sacrifice; SD: Standard Deviation; Q1: First Quartile; Q3: Third Quartile.

Table $2 \mathrm{~b}$. Volumetric measurements (mean distance, $\mathrm{mm}$ ) between post-operative (T2) and sacrifice (T3). w: weeks; BV: Buccal Volume; OV: Occlusal Volume; RW-2: Total Ridge Width at 2mm; SD: Standard Deviation; Q1: First Quartile; Q3: Third Quartile.

Table 2c. Linear measurements ( $\mathrm{mm}$ ) between pre-extraction (T1), post-operative (T2) and sacrifice (T3). RW-1: Total Ridge Width at $1 \mathrm{~mm}$; RW-2: Total Ridge Width at 2mm; RW-3: Total Ridge Width at 3mm; SD: Standard Deviation; Q1: First Quartile; Q3: Third Quartile.

Table 2 d. Linear measurements $(\mathrm{mm})$ between post-operative (T2) and sacrifice (T3). w: weeks; RW-1: Total Ridge Width at 1mm; RW-2: Total Ridge Width at 2mm; RW-3: Total Ridge Width at 3mm; SD: Standard Deviation; Q1: First Quartile; Q3: Third Quartile.

\section{Compliance with Ethical Standards}

Conflict of Interest: Nadja Naenni declares that she has no conflict of interest. Vitor Sapata declares that he has no conflict of interest. Stefan Bienz declares that he has no conflict of interest. Minas Leventis declares that he has no conflict of interest. Ronald E. Jung declares that he has no conflict of interest. Christoph H.F. Hämmerle declares that he has no conflict of interest. Daniel S. Thoma declares that he has no conflict of interest Funding: The work was supported by Sunstar Suisse SA, Etoy, Switzerland and the Clinic of Fixed and Removable Prosthodontics and Dental Material Science, Center of Dental Medicine, University of Zurich, Zurich, Switzerland

Ethical approval: All applicable international, national, and/or institutional guidelines for the care and use of animals were followed.

Informed consent: For this type of study, formal consent is not required. 


\section{References}

Araujo, M. G., Liljenberg, B. \& Lindhe, J. (2010) beta-Tricalcium phosphate in the early phase of socket healing: an experimental study in the dog. Clinical Oral Implants Research 21, 445-454. doi:10.1111/j.1600-0501.2009.01876.x.

Araujo, M. G. \& Lindhe, J. (2005) Dimensional ridge alterations following tooth extraction. An experimental study in the dog. Journal of Clinical Periodontology 32, 212-218. doi:10.1111/j.1600-051X.2005.00642.x.

Araujo, M. G. \& Lindhe, J. (2009) Ridge preservation with the use of Bio-Oss collagen: A 6-month study in the dog. Clinical Oral Implants Research 20, 433-440. doi:10.1111/j.1600-0501.2009.01705.x.

Artzi, Z., Tal, H. \& Dayan, D. (2000) Porous bovine bone mineral in healing of human extraction sockets. Part 1: histomorphometric evaluations at 9 months. Journal of Periodontology 71, 1015-1023. doi:10.1902/jop.2000.71.6.1015.

Atwood, D. A. (2001) Some clinical factors related to rate of resorption of residual ridges. 1962. Journal of Prosthetic Dentistry 86, 119-125.

Avila-Ortiz, G., Elangovan, S., Kramer, K. W., Blanchette, D. \& Dawson, D. V. (2014) Effect of alveolar ridge preservation after tooth extraction: a systematic review and meta-analysis. J Dent Res 93, 950-958. doi:10.1177/0022034514541127.

Barone, A., Aldini, N. N., Fini, M., Giardino, R., Calvo Guirado, J. L. \& Covani, U. (2008) Xenograft versus extraction alone for ridge preservation after tooth removal: a clinical and histomorphometric study. Journal of Periodontology 79, 1370-1377. doi:10.1902/jop.2008.070628.

Barone, A., Orlando, B., Cingano, L., Marconcini, S., Derchi, G. \& Covani, U. (2012) A randomized clinical trial to evaluate and compare implants placed in augmented versus non-augmented extraction sockets: 3-year results. Journal of Periodontology 83, 836-846. doi:10.1902/jop.2011.110205.

Barone, A., Ricci, M., Tonelli, P., Santini, S. \& Covani, U. (2013) Tissue changes of extraction sockets in humans: a comparison of spontaneous healing vs. ridge 
preservation with secondary soft tissue healing. Clinical Oral Implants Research 24, 1231-1237. doi:10.1111/j.1600-0501.2012.02535.x.

Barone, A., Toti, P., Quaranta, A., Alfonsi, F., Cucchi, A., Calvo-Guirado, J. L., Negri, B., Di Felice, R. \& Covani, U. (2015) Volumetric analysis of remodelling pattern after ridge preservation comparing use of two types of xenografts. A multicentre randomized clinical trial. Clin Oral Implants Res. doi:10.1111/clr.12572.

Cardaropoli, D., Tamagnone, L., Roffredo, A., Gaveglio, L. \& Cardaropoli, G. (2012) Socket preservation using bovine bone mineral and collagen membrane: a randomized controlled clinical trial with histologic analysis. Int J Periodontics Restorative Dent 32, 421-430.

Cardaropoli, G., Araujo, M. \& Lindhe, J. (2003) Dynamics of bone tissue formation in tooth extraction sites. An experimental study in dogs. Journal of Clinical Periodontology 30, 809-818.

Dahlin, C., Obrecht, M., Dard, M. \& Donos, N. (2015) Bone tissue modelling and remodelling following guided bone regeneration in combination with biphasic calcium phosphate materials presenting different microporosity. Clinical Oral Implants Research 26, 814-822. doi:10.1111/clr.12361.

Froum, S. \& Orlowski, W. (2000) Ridge preservation utilizing an alloplast prior to implant placement--clinical and histological case reports. Practical Periodontics and Aesthetic Dentistry 12, 393-402; quiz 404.

Froum, S. J., Wallace, S. S., Cho, S. C., Elian, N. \& Tarnow, D. P. (2008) Histomorphometric comparison of a biphasic bone ceramic to anorganic bovine bone for sinus augmentation: 6- to 8-month postsurgical assessment of vital bone formation. A pilot study. International Journal of Periodontics and Restorative Dentistry 28, 273-281.

Horowitz, R. A., Mazor, Z., Miller, R. J., Krauser, J., Prasad, H. S. \& Rohrer, M. D. (2009) Clinical evaluation alveolar ridge preservation with a beta-tricalcium phosphate socket graft. Compendium of Continuing Education in Dentistry 30, 588-590, 592, 594 passim; quiz 604, 606.

Jensen, S. S., Bornstein, M. M., Dard, M., Bosshardt, D. D. \& Buser, D. (2009) Comparative study of biphasic calcium phosphates with different HA/TCP ratios in 
mandibular bone defects. A long-term histomorphometric study in minipigs. Journal of biomedical materials research. Part B, Applied biomaterials 90, 171181. doi:10.1002/jbm.b.31271.

Jung, R. (2017) Alveolar ridge preservation in the esthetic zone. Perio2000 accepted.

Jung, R. E., Philipp, A., Annen, B. M., Signorelli, L., Thoma, D. S., Hammerle, C. H., Attin, T. \& Schmidlin, P. (2013) Radiographic evaluation of different techniques for ridge preservation after tooth extraction: a randomized controlled clinical trial. Journal of Clinical Periodontology 40, 90-98. doi:10.1111/jcpe.12027.

Kilkenny, C., Browne, W., Cuthill, I. C., Emerson, M. \& Altman, D. G. (2011) Animal research: reporting in vivo experiments--the ARRIVE guidelines. Journal of Cerebral Blood Flow and Metabolism 31, 991-993. doi:10.1038/jcbfm.2010.220.

Kim, J. J., Schwarz, F., Song, H. Y., Choi, Y., Kang, K. R. \& Koo, K. T. (2016) Ridge preservation of extraction sockets with chronic pathology using Bio-Oss $(R)$ Collagen with or without collagen membrane: an experimental study in dogs. Clin Oral Implants Res. doi:10.1111/clr.12870.

Lee, D. W., Pi, S. H., Lee, S. K. \& Kim, E. C. (2009) Comparative histomorphometric analysis of extraction sockets healing implanted with bovine xenografts, irradiated cancellous allografts, and solvent-dehydrated allografts in humans. International Journal of Oral and Maxillofacial Implants 24, 609-615.

Lindhe, J., Cecchinato, D., Donati, M., Tomasi, C. \& Liljenberg, B. (2014) Ridge preservation with the use of deproteinized bovine bone mineral. Clinical Oral Implants Research 25, 786-790. doi:10.1111/clr.12170.

Mardas, N., Trullenque-Eriksson, A., MacBeth, N., Petrie, A. \& Donos, N. (2015) Does ridge preservation following tooth extraction improve implant treatment outcomes: a systematic review: Group 4: Therapeutic concepts \& methods. Clinical Oral Implants Research 26 Suppl 11, 180-201. doi:10.1111/clr.12639.

Rothamel, D., Schwarz, F., Herten, M., Engelhardt, E., Donath, K., Kuehn, P. \& Becker, J. (2008) Dimensional ridge alterations following socket preservation using a nanocrystalline hydroxyapatite paste: a histomorphometrical study in dogs. International Journal of Oral and Maxillofacial Surgery 37, 741-747. doi:10.1016/j.ijom.2008.04.017. 
Scheyer, E. T., Heard, R., Janakievski, J., Mandelaris, G., Nevins, M. L., Pickering, S. R., Richardson, C. R., Pope, B., Toback, G., Velasquez, D. \& Nagursky, H. (2016) A randomized, controlled, multicentre clinical trial of post-extraction alveolar ridge preservation. J Clin Periodontol. doi:10.1111/jcpe.12623.

Schneider, D., Schmidlin, P. R., Philipp, A., Annen, B. M., Ronay, V., Hammerle, C. H., Attin, T. \& Jung, R. E. (2014) Labial soft tissue volume evaluation of different techniques for ridge preservation after tooth extraction: a randomized controlled clinical trial. Journal of Clinical Periodontology 41, 612-617. doi:10.1111/jcpe.12246.

Schropp, L., Wenzel, A., Kostopoulos, L. \& Karring, T. (2003) Bone healing and soft tissue contour changes following single-tooth extraction: a clinical and radiographic 12-month prospective study. International Journal of Periodontics and Restorative Dentistry 23, 313-323.

Shi, B., Zhou, Y., Wang, Y. N. \& Cheng, X. R. (2007) Alveolar ridge preservation prior to implant placement with surgical-grade calcium sulfate and platelet-rich plasma: a pilot study in a canine model. International Journal of Oral and Maxillofacial Implants 22, 656-665.

Sisti, A., Canullo, L., Mottola, M. P., Covani, U., Barone, A. \& Botticelli, D. (2012) Clinical evaluation of a ridge augmentation procedure for the severely resorbed alveolar socket: multicenter randomized controlled trial, preliminary results. Clinical Oral Implants Research 23, 526-535. doi:10.1111/j.1600-0501.2011.02386.x.

Spinato, S., Galindo-Moreno, P., Zaffe, D., Bernardello, F. \& Soardi, C. M. (2014) Is socket healing conditioned by buccal plate thickness? A clinical and histologic study 4 months after mineralized human bone allografting. Clinical Oral Implants Research 25, e120-126. doi:10.1111/clr.12073.

Tallgren, A. (1972) The continuing reduction of the residual alveolar ridges in complete denture wearers: a mixed-longitudinal study covering 25 years. Journal of Prosthetic Dentistry 27, 120-132.

Tan, W. L., Wong, T. L., Wong, M. C. \& Lang, N. P. (2012) A systematic review of postextractional alveolar hard and soft tissue dimensional changes in humans. Clinical Oral Implants Research 23 Suppl 5, 1-21. doi:10.1111/j.16000501.2011.02375.x. 
Thoma, D. S., Jung, R. E., Schneider, D., Cochran, D. L., Ender, A., Jones, A. A., Gorlach, C., Uebersax, L., Graf-Hausner, U. \& Hammerle, C. H. (2010) Soft tissue volume augmentation by the use of collagen-based matrices: a volumetric analysis. Journal of Clinical Periodontology 37, 659-666. doi:10.1111/j.1600051X.2010.01581.x.

Vignoletti, F., Matesanz, P., Rodrigo, D., uero, E., Martin, C. \& Sanz, M. (2012) Surgical protocols for ridge preservation after tooth extraction. A systematic review. Clinical Oral Implants Research 23 Suppl 5, 22-38. doi:10.1111/j.16000501.2011.02331.x. 


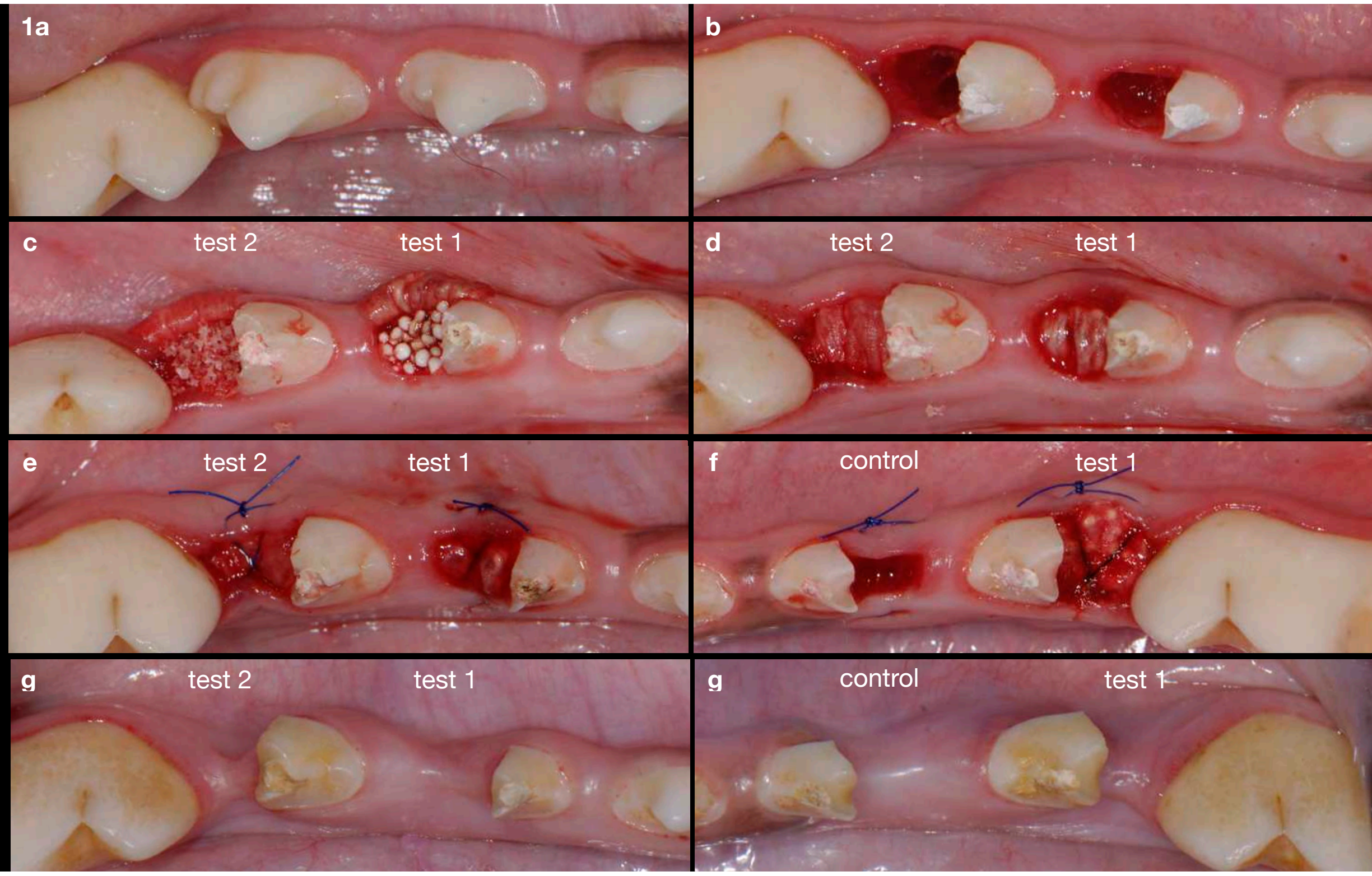

Figure 1 


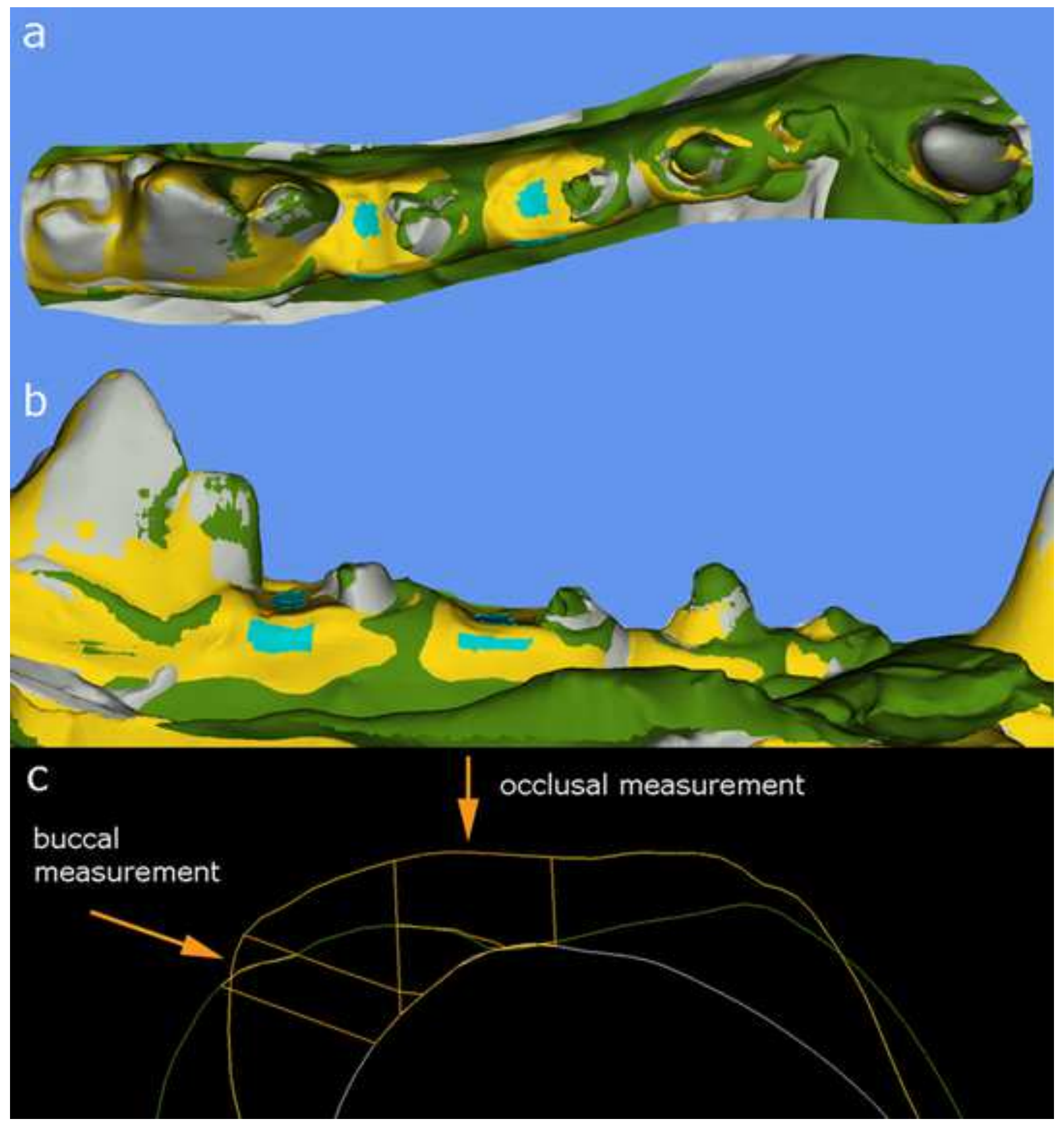

Figure 2 


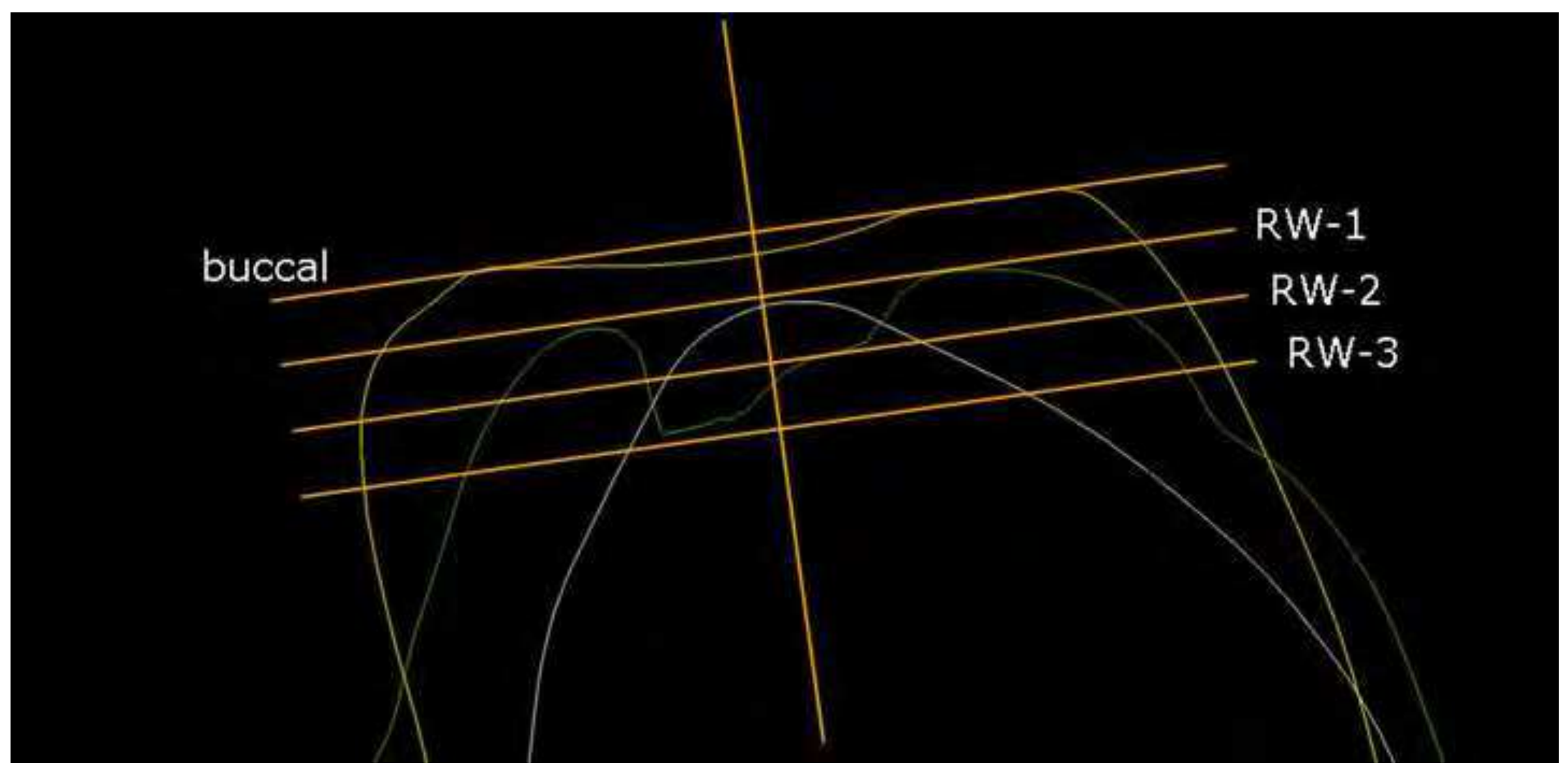

Figure 3 


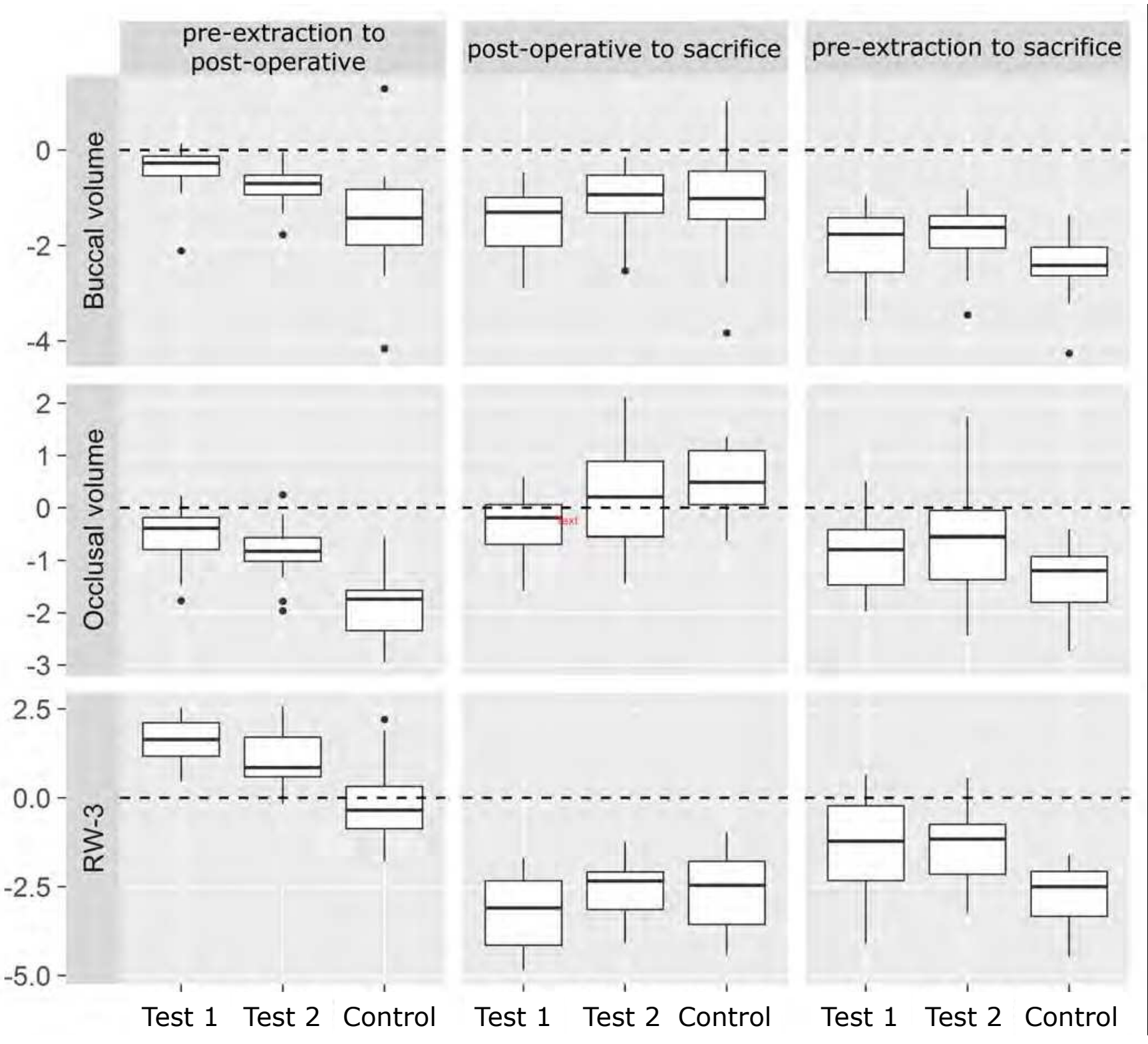

Figure 4 
a

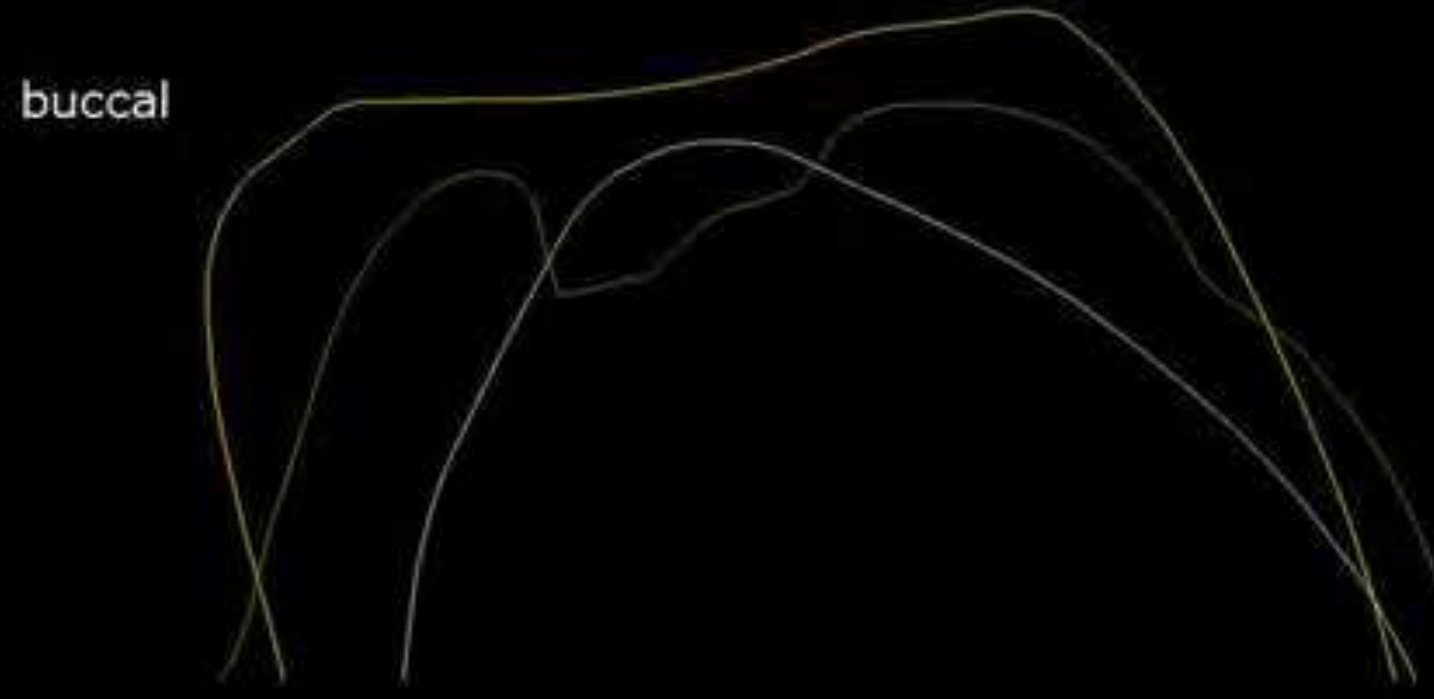

b

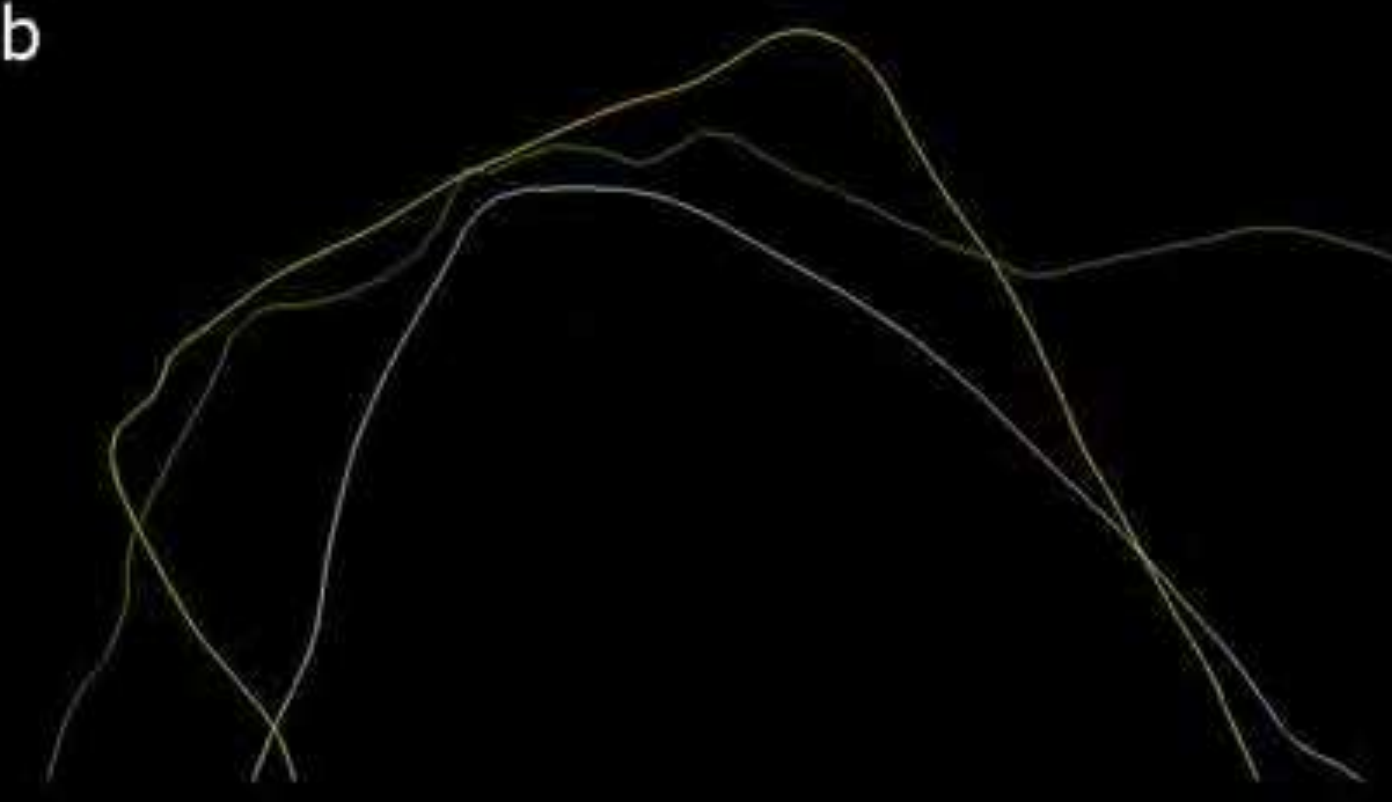

C

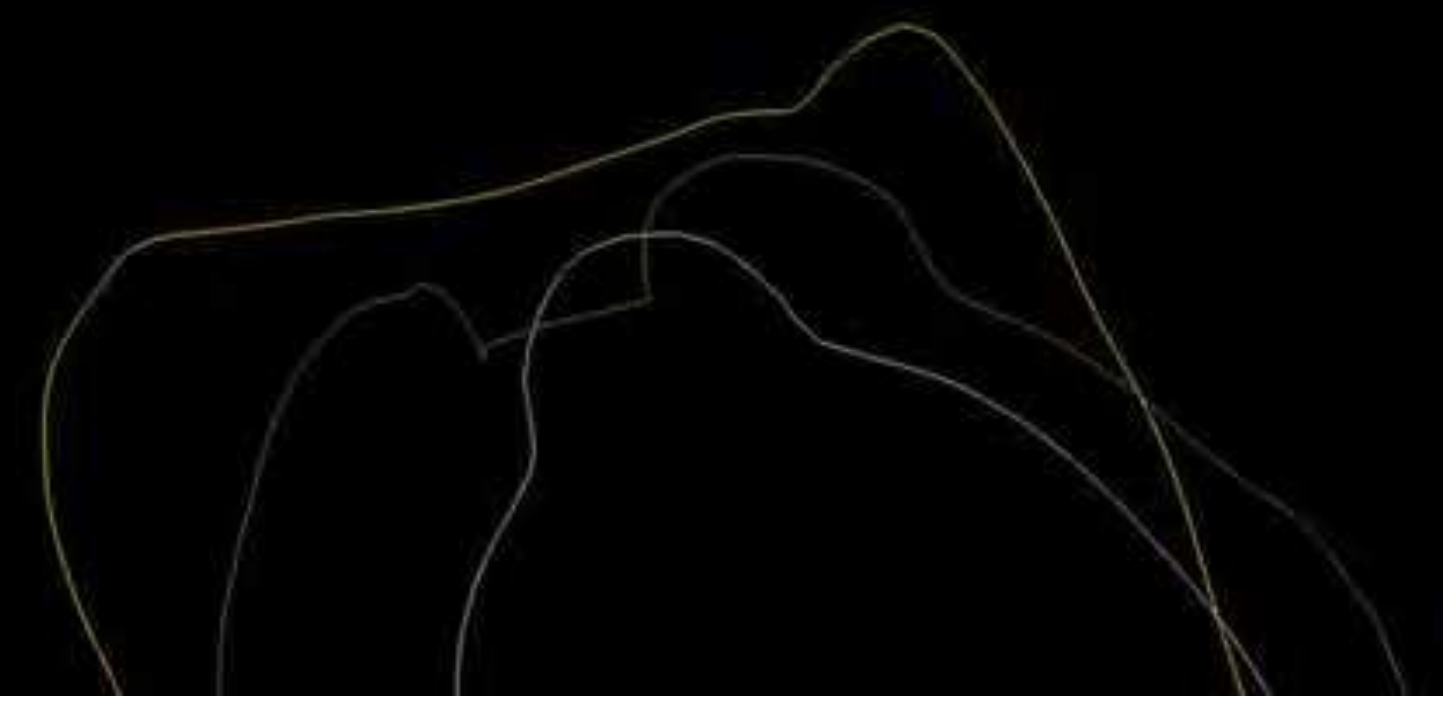

Figure 5 
Table 1. Study schedule.

\begin{tabular}{|l|c|c|c|c|}
\cline { 3 - 5 } \multicolumn{2}{c|}{} & \multicolumn{3}{c|}{ Treatment groups and number of sites } \\
\hline Time points & $\begin{array}{c}\text { Number of } \\
\text { (sacrifice) }\end{array}$ & Test 1 & Test 2 & Control \\
& $\begin{array}{c}\text { animals per time- } \\
\text { point }\end{array}$ & 5 & & \\
\hline 4 weeks & 5 & 7 & 7 & 6 \\
\hline 8 weeks & 5 & 7 & 7 & 6 \\
\hline 16 weeks & 6 & 8 & 8 & 6 \\
\hline
\end{tabular}

Table 1 
Table 2a. Volumetric measurements (mean distance, $\mathrm{mm}$ ) between preextraction (T1), post-operative (T2) and sacrifice (T3)

\begin{tabular}{|c|c|c|c|c|c|c|}
\hline \multirow[b]{2}{*}{ T1-T2 } & \multicolumn{3}{|c|}{ BV (mm) } & \multicolumn{3}{|c|}{ OV $(\mathrm{mm})$} \\
\hline & $\begin{array}{c}\text { Test } 1 \\
(n=21)\end{array}$ & $\begin{array}{c}\text { Test } 2 \\
(n=23)\end{array}$ & $\begin{array}{l}\text { Control } \\
(n=18)\end{array}$ & $\begin{array}{c}\text { Test } 1 \\
(n=21)\end{array}$ & $\begin{array}{c}\text { Test } 2 \\
(n=23)\end{array}$ & $\begin{array}{l}\text { Control } \\
(n=18)\end{array}$ \\
\hline Mean & $-0,40$ & $-0,73$ & $-1,45$ & $-0,52$ & $-0,86$ & $-1,89$ \\
\hline SD & 0,47 & 0,40 & 1,11 & 0,54 & 0,54 & 0,66 \\
\hline Median & $-0,27$ & $-0,70$ & $-1,43$ & $-0,39$ & $-0,82$ & $-1,74$ \\
\hline Q1 & $-0,54$ & $-0,89$ & $-1,99$ & $-0,79$ & $-1,02$ & $-2,34$ \\
\hline \multirow[t]{2}{*}{ Q3 } & $-0,13$ & $-0,53$ & $-0,83$ & $-0,19$ & $-0,57$ & $-1,57$ \\
\hline & \multicolumn{3}{|c|}{ BV $(\mathrm{mm})$} & \multicolumn{3}{|c|}{ OV $(\mathrm{mm})$} \\
\hline T1-T3 & $\begin{array}{c}\text { Test } 1 \\
(n=21)\end{array}$ & $\begin{array}{l}\text { Test } 2 \\
(n=23)\end{array}$ & $\begin{array}{l}\text { Control } \\
(n=18)\end{array}$ & $\begin{array}{c}\text { Test } 1 \\
(n=21)\end{array}$ & $\begin{array}{c}\text { Test } 2 \\
(n=23)\end{array}$ & $\begin{array}{l}\text { Control } \\
(n=18)\end{array}$ \\
\hline Mean & $-1,95$ & $-1,75$ & $-2,43$ & $-0,85$ & $-0,67$ & $-1,38$ \\
\hline SD & 0,71 & 0,67 & 0,68 & 0,71 & 0,97 & 0,64 \\
\hline Median & $-1,76$ & $-1,62$ & $-2,42$ & $-0,79$ & $-0,55$ & $-1,19$ \\
\hline Q1 & $-2,56$ & $-2,17$ & $-2,63$ & $-1,47$ & $-1,37$ & $-1,80$ \\
\hline Q3 & $-1,42$ & $-1,38$ & $-2,03$ & $-0,42$ & $-0,05$ & $-0,93$ \\
\hline
\end{tabular}

BV: Buccal Volume; OV: Occlusal Volume; T1: Pre-extraction; T2: Postoperative; T3: Sacrifice; SD: Standard Deviation; Q1: First Quartile; Q3: Third Quartile.

Table 2a 


\begin{tabular}{|c|c|c|c|c|c|c|c|c|c|c|c|c|c|c|c|c|c|c|}
\hline \multirow[b]{3}{*}{ T2-T3 } & \multicolumn{9}{|c|}{ BV (mm) } & \multicolumn{9}{|c|}{ OV (mm) } \\
\hline & \multicolumn{3}{|c|}{ Test 1} & \multicolumn{3}{|c|}{ Test 2} & \multicolumn{3}{|c|}{ Control } & \multicolumn{3}{|c|}{ Test 1} & \multicolumn{3}{|c|}{ Test 2} & \multicolumn{3}{|c|}{ Control } \\
\hline & $\begin{array}{c}4 w \\
(n=7)\end{array}$ & $\begin{array}{c}8 w \\
(n=7)\end{array}$ & $\begin{array}{c}16 w \\
(n=7)\end{array}$ & $\begin{array}{c}4 w \\
(n=7)\end{array}$ & $\begin{array}{c}8 w \\
(n=7)\end{array}$ & $\begin{array}{c}16 w \\
(n=9)\end{array}$ & $\begin{array}{c}4 w \\
(n=6)\end{array}$ & $\begin{array}{c}8 w \\
(n=6)\end{array}$ & $\begin{array}{c}16 w \\
(n=6)\end{array}$ & $\begin{array}{c}4 w \\
(n=7)\end{array}$ & $\begin{array}{c}8 w \\
(n=7)\end{array}$ & $\begin{array}{c}16 w \\
(n=7)\end{array}$ & $\begin{array}{c}4 w \\
(n=7)\end{array}$ & $\begin{array}{c}8 w \\
(n=7)\end{array}$ & $\begin{array}{c}16 w \\
(n=9)\end{array}$ & $\begin{array}{c}4 w \\
(n=6)\end{array}$ & $\begin{array}{c}8 w \\
(n=6)\end{array}$ & $\begin{array}{c}16 w \\
(n=6)\end{array}$ \\
\hline Mean & $-1,32$ & $-1,82$ & $-1,50$ & $-0,99$ & $-1,29$ & $-0,83$ & $-0,55$ & $-1,51$ & $-0,90$ & $-0,30$ & $-0,39$ & $-0,30$ & 0,62 & $-0,28$ & 0,20 & 0,86 & 0,35 & 0,31 \\
\hline SD & 0,72 & 0,57 & 0,86 & 0,60 & 0,91 & 0,61 & 1,05 & 1,18 & 1,16 & 0,57 & 0,51 & 0,72 & 0,60 & 0,98 & 0,94 & 0,44 & 0,70 & 0,59 \\
\hline Median & $-1,08$ & $-1,84$ & $-1,44$ & $-0,88$ & $-0,93$ & $-0,83$ & $-0,71$ & $-1,09$ & $-1,01$ & $-0,08$ & $-0,33$ & $-0,35$ & 0,75 & $-0,39$ & 0,17 & 1,01 & 0,27 & 0,38 \\
\hline Q1 & $-1,27$ & $-2,24$ & $-1,92$ & $-1,20$ & $-1,96$ & $-0,99$ & $-1,40$ & $-1,51$ & $-1,22$ & $-0,46$ & $-0,76$ & $-0,57$ & 0,29 & $-1,06$ & $-0,71$ & 0,49 & $-0,18$ & 0,05 \\
\hline Q3 & $-0,93$ & $-1,28$ & $-0,93$ & $-0,65$ & $-0,69$ & $-0,49$ & 0,10 & $-0,80$ & $-0,04$ & 0,01 & $-0,02$ & 0,18 & 1,04 & 0,39 & 0,30 & 1,12 & 0,99 & 0,63 \\
\hline
\end{tabular}

w: weeks; BV: Buccal Volume; OV: Occlusal Volume; T2: Post-operative; T3: Sacrifice; SD: Standard Deviation; Q1: First Quartile; Q3: Third Quartile.

Table $2 b$ 
Table 2c. Linear measurements $(\mathrm{mm})$ between pre-extraction (T1), post-operative (T2) and sacrifice (T3)

\begin{tabular}{|c|c|c|c|c|c|c|c|c|c|c|c|c|}
\hline \multirow[b]{2}{*}{ T1-T2 } & \multicolumn{3}{|c|}{ RW-1 (mm) } & \multicolumn{3}{|c|}{ RW-2 ( $\mathrm{mm})$} & \multicolumn{3}{|c|}{ RW-3 (mm) } & \multicolumn{3}{|c|}{ RW-avg (mm) } \\
\hline & $\begin{array}{c}\text { Test } 1 \\
(n=19)\end{array}$ & $\begin{array}{c}\text { Test } 2 \\
(n=23)\end{array}$ & $\begin{array}{l}\text { Control } \\
(n=18)\end{array}$ & $\begin{array}{c}\text { Test } 1 \\
(n=19)\end{array}$ & $\begin{array}{c}\text { Test } 2 \\
(n=23)\end{array}$ & $\begin{array}{l}\text { Control } \\
(n=18)\end{array}$ & $\begin{array}{c}\text { Test } 1 \\
(n=17)\end{array}$ & $\begin{array}{c}\text { Test } 2 \\
(n=19)\end{array}$ & $\begin{array}{l}\text { Control } \\
(n=18)\end{array}$ & $\begin{array}{c}\text { Test } 1 \\
(n=21)\end{array}$ & $\begin{array}{c}\text { Test } 2 \\
(n=23)\end{array}$ & $\begin{array}{l}\text { Control } \\
(n=18)\end{array}$ \\
\hline MEAN & $-0,74$ & $-1,76$ & $-4,15$ & 0,68 & 0,16 & $-1,79$ & 1,53 & 1,08 & $-0,14$ & 0,45 & $-0,22$ & $-2,02$ \\
\hline SD & 1,65 & 1,95 & 1,87 & 1,38 & 0,78 & 1,51 & 0,67 & 0,79 & 1,06 & 1,05 & 0,96 & 1,27 \\
\hline MEDIAN & $-0,44$ & $-1,18$ & $-4,97$ & 0,50 & 0,01 & $-1,15$ & 1,64 & 0,85 & $-0,35$ & 0,59 & $-0,13$ & $-2,09$ \\
\hline Q1 & $-0,73$ & $-1,95$ & $-5,38$ & $-0,21$ & $-0,19$ & $-2,15$ & 1,17 & 0,62 & $-0,87$ & 0,14 & $-0,39$ & $-2,80$ \\
\hline \multirow[t]{2}{*}{ Q3 } & 0,14 & $-0,46$ & $-2,07$ & 1,01 & 0,42 & $-0,81$ & 2,11 & 1,71 & 0,32 & 0,79 & 0,30 & $-0,89$ \\
\hline & \multicolumn{3}{|c|}{ RW-1 (mm) } & \multicolumn{3}{|c|}{ RW-2 (mm) } & \multicolumn{3}{|c|}{ RW-3 (mm) } & \multicolumn{3}{|c|}{ RW-avg (mm) } \\
\hline T1-T3 & $\begin{array}{c}\text { Test } 1 \\
(n=19)\end{array}$ & $\begin{array}{c}\text { Test } 2 \\
(n=23)\end{array}$ & $\begin{array}{l}\text { Control } \\
(n=18)\end{array}$ & $\begin{array}{c}\text { Test } 1 \\
(n=19)\end{array}$ & $\begin{array}{c}\text { Test } 2 \\
(n=23)\end{array}$ & $\begin{array}{l}\text { Control } \\
(n=18)\end{array}$ & $\begin{array}{c}\text { Test } 1 \\
(n=17)\end{array}$ & $\begin{array}{c}\text { Test } 2 \\
(n=19)\end{array}$ & $\begin{array}{l}\text { Control } \\
(n=18)\end{array}$ & $\begin{array}{c}\text { Test } 1 \\
(n=21)\end{array}$ & $\begin{array}{c}\text { Test } 2 \\
(n=23)\end{array}$ & $\begin{array}{l}\text { Control } \\
(n=18)\end{array}$ \\
\hline MEAN & $-4,07$ & $-4,18$ & $-5,38$ & $-2,73$ & $-2,67$ & $-4,02$ & $-1,40$ & $-1,45$ & $-2,76$ & $-2,74$ & $-2,82$ & $-4,05$ \\
\hline SD & 1,65 & 1,55 & 1,29 & 1,65 & 1,45 & 1,35 & 1,34 & 1,07 & 0,94 & 1,51 & 1,28 & 1,12 \\
\hline MEDIAN & $-3,93$ & $-3,70$ & $-5,55$ & $-2,47$ & $-2,06$ & $-3,60$ & $-1,22$ & $-1,16$ & $-2,50$ & $-2,51$ & $-2,04$ & $-3,85$ \\
\hline Q1 & $-4,64$ & $-5,70$ & $-6,39$ & $-3,25$ & $-3,56$ & $-4,92$ & $-2,33$ & $-2,28$ & $-3,34$ & $-3,25$ & $-3,82$ & $-5,02$ \\
\hline Q3 & $-2,79$ & $-3,04$ & $-4,70$ & $-1,60$ & $-1,59$ & $-3,10$ & $-0,23$ & $-0,75$ & $-2,07$ & $-1,70$ & $-1,81$ & $-3,27$ \\
\hline
\end{tabular}

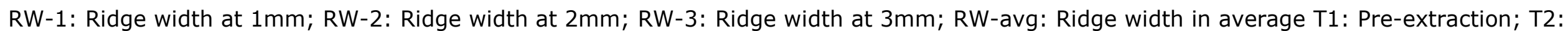
Post-operative; T3: Sacrifice; SD: Standard Deviation; Q1: First Quartile; Q3: Third Quartile.

Table 2c 


\begin{tabular}{|c|c|c|c|c|c|c|c|c|c|}
\hline \multirow[b]{3}{*}{ T2-T3 } & \multicolumn{9}{|c|}{ RW-1 (m } \\
\hline & \multicolumn{3}{|c|}{ Test 1} & \multicolumn{3}{|c|}{ Test 2} & \multicolumn{3}{|c|}{ Control } \\
\hline & $\begin{array}{l}4 w \\
(n=7)\end{array}$ & $\begin{array}{c}8 w \\
(n=7)\end{array}$ & $\begin{array}{c}16 w \\
(n=7)\end{array}$ & $\begin{array}{c}4 w \\
(n=6)\end{array}$ & $\begin{array}{c}8 w \\
(n=7)\end{array}$ & $\begin{array}{c}16 \mathrm{w} \\
(\mathrm{n}=9)\end{array}$ & $\underset{(n=5)}{4 w}$ & $\begin{array}{c}8 w \\
(n=6)\end{array}$ & $\begin{array}{l}16 w \\
(n=6)\end{array}$ \\
\hline Mean & $-3,62$ & $-3,22$ & $-3,16$ & $-1,75$ & $-2,75$ & $-2,68$ & $-1,42$ & $-0,22$ & $-2,06$ \\
\hline SD & 1,26 & 2,12 & 1,73 & 2,29 & 2,26 & 1,72 & 1,80 & 1,89 & 1,75 \\
\hline Median & $-3,18$ & $-3,27$ & $-2,65$ & $-2,58$ & $-2,27$ & $-2,60$ & $-0,53$ & $-0,79$ & $-1,99$ \\
\hline Q1 & $-4,25$ & $-4,44$ & $-4,18$ & $-3,08$ & $-4,43$ & $-3,97$ & $-2,81$ & $-1,15$ & $-2,96$ \\
\hline \multirow[t]{3}{*}{ Q3 } & $-2,98$ & $-2,26$ & $-1,80$ & $-0,31$ & $-0,84$ & $-1,52$ & $-0,12$ & 0,55 & $-1,60$ \\
\hline & \multicolumn{9}{|c|}{ RW-2 (mm) } \\
\hline & \multicolumn{3}{|c|}{ Test 1} & \multicolumn{3}{|c|}{ Test 2} & \multicolumn{3}{|c|}{ Control } \\
\hline T2-T3 & $\begin{array}{l}4 w \\
(n=5)\end{array}$ & $\begin{array}{c}8 w \\
(n=7)\end{array}$ & $\begin{array}{l}16 w \\
(n=7)\end{array}$ & $\begin{array}{l}4 w \\
(n=7)\end{array}$ & $\begin{array}{c}8 w \\
(n=7)\end{array}$ & $\begin{array}{c}16 w \\
(n=9)\end{array}$ & $\begin{array}{c}4 w \\
(n=6)\end{array}$ & $\begin{array}{c}8 w \\
(n=6)\end{array}$ & $\begin{array}{c}16 w \\
(n=6)\end{array}$ \\
\hline Mean & $-4,28$ & $-3,84$ & $-2,64$ & $-2,24$ & $-3,59$ & $-2,68$ & $-1,75$ & $-1,55$ & $-3,41$ \\
\hline SD & 1,83 & 1,64 & 1,18 & 0,64 & 2,13 & 1,16 & 1,34 & 1,09 & 1,96 \\
\hline Median & $-3,98$ & $-2,83$ & $-2,23$ & $-2,08$ & $-3,25$ & $-2,95$ & $-2,37$ & $-1,62$ & $-2,69$ \\
\hline Q1 & $-4,81$ & $-4,71$ & $-3,13$ & $-2,72$ & $-4,36$ & $-3,89$ & $-2,58$ & $-2,20$ & $-4,85$ \\
\hline \multirow[t]{3}{*}{ Q3 } & $-3,15$ & $-2,77$ & $-1,97$ & $-1,79$ & $-2,30$ & $-1,65$ & $-1,14$ & $-1,17$ & $-1,88$ \\
\hline & \multicolumn{9}{|c|}{ RW-3 (mm) } \\
\hline & \multicolumn{3}{|c|}{ Test } & \multicolumn{3}{|c|}{ Control } & \multicolumn{3}{|c|}{ Sham } \\
\hline T2-T3 & $\begin{array}{c}4 w \\
(n=3)\end{array}$ & $\begin{array}{c}8 w \\
(n=7)\end{array}$ & $\begin{array}{l}16 w \\
(n=7)\end{array}$ & $\begin{array}{c}4 w \\
(n=5)\end{array}$ & $\begin{array}{c}8 w \\
(n=6)\end{array}$ & $\begin{array}{c}16 w \\
(n=8)\end{array}$ & $\begin{array}{c}4 w \\
(n=6)\end{array}$ & $\begin{array}{c}8 \mathrm{w} \\
(\mathrm{n}=6)\end{array}$ & $\begin{array}{c}16 w \\
(n=6)\end{array}$ \\
\hline Mean & $-3,14$ & $-3,52$ & $-2,96$ & $-1,87$ & $-2,88$ & $-2,71$ & $-2,99$ & $-1,84$ & $-3,04$ \\
\hline SD & 1,35 & 0,89 & 1,03 & 0,45 & 0,85 & 0,84 & 1,05 & 0,75 & 1,04 \\
\hline Median & $-3,10$ & $-3,68$ & $-3,00$ & $-1,98$ & $-3,04$ & $-2,46$ & $-3,30$ & $-1,88$ & $-3,10$ \\
\hline Q1 & $-3,80$ & $-4,16$ & $-3,27$ & $-2,20$ & $-3,20$ & $-3,29$ & $-3,84$ & $-2,20$ & $-3,73$ \\
\hline Q3 & $-2,46$ & $-2,89$ & $-2,30$ & $-1,59$ & $-2,46$ & $-2,30$ & $-2,24$ & $-1,25$ & $-2,26$ \\
\hline
\end{tabular}

w: weeks; RW-1: Ridge width at 1mm; RW-2: Ridge width at 2mm; RW-3: Ridge width at 3mm; T2: Post-operative; T3: Sacrifice n; SD: Standard Deviation; Q1: First Quartile; Q3: Third Quartile. 